\title{
First-in-man intraglandular implantation of stromal vascular fraction and adipose-derived stem cells plus platelet-rich plasma in irradiation-induced gland damage: a case study
}

\author{
This article was published in the following Dove Press journal: \\ International Medical Case Reports Journal \\ 16 August 2017 \\ Number of times this article has been viewed
}

\section{Kristin Comella' \\ Walter Bell ${ }^{2}$ \\ 'US Stem Cell, Inc, Sunrise, FL, USA; ${ }^{2}$ South African Stem Cell Institute, Parys, South Africa}

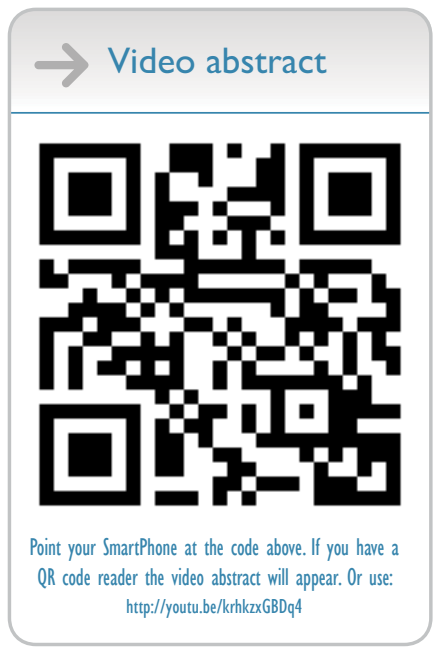

Correspondence: Kristin Comella US Stem Cell, Inc, 13794 Northwest 4th Street, Suite 212, Sunrise, FL 33325, USA $\mathrm{Tel}+$ I 954835 I500

Email kcomella@us-stemcell.com
Background: Stromal vascular fraction (SVF) is a mixture of cells which can be isolated from a mini-lipoaspirate of fat tissue. Platelet-rich plasma (PRP) is a mixture of growth factors and other nutrients which can be obtained from peripheral blood. Adipose-derived stem/stromal cells (ADSCs) can be isolated from fat tissue and expanded in culture. The SVF includes a variety of different cells such as ADSCs, pericytes, endothelial/progenitor cells, and a mix of different growth factors. The adipocytes (fat cells) can be removed via centrifugation. Here, we describe the rationale and, to our knowledge, the first clinical implementation of SVF and PRP followed by repeat dosing of culture-expanded ADSCs into a patient with severe xerostomia postirradiation. Methods: Approximately $120 \mathrm{mLs}$ of adipose tissue was removed via mini-lipoaspirate procedure under local anesthetic. The SVF was prepared from half of the fat and resuspended in PRP. The mixture was delivered via ultrasound directly into the submandibular and parotid glands on both the right and left sides. The remaining $60 \mathrm{mLs}$ of fat was processed to culture-expand ADSCs. The patient received seven follow-up injections of the ADSCs plus PRP at 5, 8, 16, 18, 23, 28, and 31 months postliposuction. The subject was monitored over a period of 31 months for safety (adverse events), glandular size via ultrasound and saliva production.

Results: Throughout the 31-month monitoring period, no safety events such as infection or severe adverse events were reported. The patient demonstrated an increase in gland size as measured by ultrasound which corresponded to increased saliva production.

Conclusion: Overall, the patient reported improved quality of life and willingness to continue treatments. The strong safety profile and preliminary efficacy results warrant larger studies to determine if this is a feasible treatment plan for patients postradiation.

Keywords: adipose tissue, ADSCs, cell therapy, MSCs, PRP, stem cells, SVF, xerostomia

\section{Background}

Xerostomia or severe dry mouth is the lack of production of appropriate amounts of saliva. Patients who undergo radiation or chemotherapy treatments for neck and head cancers may develop xerostomia as a result of damaged salivary glands. The salivary glands include the parotid (located between the ear and the jaw) and submandibular glands (located under the jaw). Radiotherapy of the glands causes a variety of structural damages specifically cell death, edema, formation of fibrous tissue, and hypovascularization. ${ }^{1}$ Extreme dry mouth leads to a reduced quality of life with difficulty speaking and swallowing. Current therapies do not address the underlying issues and pathology. ${ }^{2}$ Regenerative treatment for salivary gland tissue repair is a novel therapeutic option due 
to the cell-to-cell interactions of the germ layers. ${ }^{3,4}$ Several preclinical animal studies have addressed the clinical benefit of MSCs on dysfunctional salivary glands. ${ }^{5}$

Adult stem cells are currently being studied for use in a variety of diseases and disorders. MSCs, which are a subpopulation of nonhematopoietic progenitor cells, may be obtained from multiple tissue sources in the adult human. These cells are described as multipotential and have the capacity to differentiate down various pathways in vitro. In addition, MSCs may have a broad range of indications in various diseases or injuries due to their ability to repair damaged tissues or lesions. ${ }^{6,7}$ MSCs can multiply and form various tissue types and may represent a realistic biologic therapy. In addition, the regenerative potential of MSCs in radiation-damaged tissue is promising due to their relatively high radiation resistance. ${ }^{8}$

These cells demonstrate properties of angiogenesis and mitogenesis and can therefore promote wound healing. The MSCs may induce a paracrine effect leading to reduced inflammation, cell death, and tissue fibrosis. The cell-to-cell communication of the secreted biological factors can regulate the regeneration of damaged tissues in the body. The pericyte which coats the small vessels and capillaries in all tissues of the body is the precursor to the MSC and can become activated in injury. At this point, the cell is converted into a medicinal MSC with immunomodulatory properties. The cells call for help to the damaged tissue establishing a trophic environment primed to heal with a mixture of cytokines and molecules. ${ }^{9}$

Fat tissue has recently been established as a plentiful source of MSCs. A mini-lipoaspirate procedure can easily be performed in an outpatient facility and yield large numbers of cells from the fat sample. The multipotential stem cells present in the fat are called ADSCs and can differentiate into bone, muscle, fat, and cartilage in vitro. ${ }^{10}$ ADSCs express many different cytokines and growth factors which contribute to the paracrine effect to promote healing and repair of damaged tissue. ADSCs have been shown to promote the formation of new blood vessels or angiogenesis in combination with the regulation of the local inflammation process. ${ }^{11,12}$

The SVF which includes a variety of cells in addition to the ADSCs can be separated from the fat tissue in 30-90 minutes bedside to the patient after the mini-lipoaspirate procedure. The population is depleted of the adipocytes or fat cells and expresses various growth factors. The population of SVF includes a high percentage of CD34+ cells. ${ }^{13}$ CD34 is expressed on hematopoietic cells, MSCs, and pericytes. It is believed that this cluster of differentiation is present within the peri-endothelial location and may be responsible for the stabilization of endothelial networks. SVF has successfully been used in a variety of clinical applications ranging from orthopedics to cardiovascular disease. ${ }^{14-16}$ Because there are a high amount of MSCs and a low amount of white blood cells, adipose tissue is becoming the preferred source for in-clinic cellular medicine over bone marrow. ${ }^{17}$ It has also been demonstrated that adipose tissue is abundant in pericytes which can convert into MSCs with medicinal properties. ${ }^{18,19}$

Patients with xerostomia postradiation have severely damaged gland tissue. Current treatment protocols following radiotherapy may only relieve symptoms temporarily and are insufficient. ${ }^{20}$ Regenerative therapies represent a new approach to repair the neuronal and vascular structures that produce saliva. ${ }^{21}$ Injected cells may work to either prevent damage from radiation ${ }^{22}$ or repair the damage created. ${ }^{23}$ Stem cells may provide an attractive approach to tissue regeneration in the glands by promoting healing, reducing inflammation, and remodeling/repairing scarred tissue. Because fat collection is a well-established method, the SVF collection of cells and reintroduction into damaged tissue may represent a safe novel therapeutic approach.

According to An et al, ADSCs exposed to hypoxic conditions can be systemically infused into mice following irradiation to improve irradiation-induced salivary hypofunction. The cells may allow for tissue remodeling due to the paracrine effect and provide for radioprotection. ${ }^{24}$ Several groups have demonstrated that cells from adipose tissue ${ }^{25,26}$ or bone marrow ${ }^{27}$ can be cocultured with gland cells. The cells express salivary gland-related markers and can differentiate down various tissue pathways.

Several groups have reported on the use of MSCs in preclinical animal models of salivary gland damage induced by radiation. Fang et al reported on the use of bone marrow cellular components in irradiated salivary glands of mice. ${ }^{28}$ These injections restored saliva flow and protected salivary cells and blood vessels from irradiated damage. In addition, culture-expanded bone marrow MSCs can migrate to damaged salivary glands after either intravenous or intraglandular injection. ${ }^{29}$ Histology of damaged glandular tissue that had been injected with MSCs demonstrated higher concentrations of leukocytes, macrophages, and MSCs as compared to controls. This study indicated that MSCs could be retained in the damaged tissue and recruited cells to the area to promote healing.

Another group discovered that conditioned media used to grow ADSCs could be isolated and infused into mice following irradiation. The mice receiving injections had 
increased salivation as well as higher levels of salivary proteins relative to the control group. ${ }^{24}$ Xiong et al showed that culture-expanded ADSCs injected directly into the glands of rats following irradiation could lead to tissue remodeling with more blood vessel supply, less cellular death, and less fibrosis. ${ }^{30}$ According to quantitative reverse transcription PCR, treated rats also revealed higher expression of growth factors with evidence of differentiation of the ADSCs into acinar and ductal cells by immunohistochemical analysis.

Chen et al reported on the use of ADSCs and platelet rich fibrin (PRF) in the repair of a maxillofacial soft tissue defect in irradiated pigs. ${ }^{31}$ Both PRF and ADSCs facilitated repair in damaged glands, and the combined use was more effective than either alone. The treated groups had significantly higher amounts of blood vessels with less dead cells.

We report the first-in-man intraglandular injection of SVF followed by repeat injection of ADSCs suspended in PRP in a patient with xerostomia following radiation therapy.

\section{Methods}

Study design

This first-in-man case study was completed on a 54-year-old male with severe xerostomia postirradiation due to throat cancer. Written informed consent was obtained from the patient for treatment and for publishing the study. SVF was injected into the right and left submandibular and parotid glands under ultrasound guidance. The patient received seven follow-up injections of the ADSCs plus PRP at 5, $8,16,18,23,28$, and 31 months postliposuction. Clinical evaluations were completed at each time point. The patient was monitored for serious adverse events to identify any fatal or life-threatening event that led to hospitalizations or required major medical intervention. Weight, blood pressure, height, and pulse were recorded as the physical parameters. The patient was evaluated for gland size by ultrasound using the same sonographer and machine.

\section{Cell preparation and study intervention}

Using an infiltration cannula, a tumescent solution was administered locally into the subcutaneous space into the flanks. Using a 3-mm Mercedes cannula, approximately $120 \mathrm{mLs}$ of fat was collected into a Toomey syringe. The SVF was isolated using a commercially available collection kit and enzyme (Adipocell Enzyme; US Stem Cell, Inc, Sunrise, FL, USA). Half of the cells were prepared for the final SVF pellet and half of the cells were placed into culture expansion. Approximately 1-3 mLs of autologous PRP was used to resuspend the final pellet of SVF. PRP was prepared by centrifuging autologous peripheral blood at $500 \mathrm{~g}$ for 8 minutes. The remaining SVF was culture expanded to obtain pure populations of ADSCs. Briefly, the cells were placed into polypropylene dishes in a basal medium supplemented with $10 \%$ fetal bovine serum and proprietary growth factors. Nonadherent cells were washed away at media feeds which were completed every 3-4 days until confluence. Cells were passaged approximately 3-4 times until preparing doses of 10 million cells each.

The first series of injections containing SVF resuspended in PRP was prepared and reintroduced back into the patient within 4 hours. The SVF was divided into four injections of $1.5 \mathrm{mLs}$ of PRP each. The volume was introduced into the submandibular and parotid salivary glands on each side under ultrasound guidance. At each follow-up, the patient received 2.5 million ADSCs resuspended in $1.5 \mathrm{mLs}$ of PRP in both submandibular and parotid glands.

\section{Results}

\section{Adipose and SVF collection}

The mini-lipoaspirate procedure was uneventful with no safety incidences reported. After isolating the SVF and removing the adipocyte population, approximately 60-100 million nucleated cells remained. Half of the cells were prepared for direct injection and half for culture expansion. As reported in previous publications, the SVF population typically expressed greater than 50\% CD34, with high viability $(>90 \%)$. The cells also demonstrated the ability to differentiate down various pathways such as adipogenesis, osteogenesis, and chondrogenesis. ${ }^{14}$

\section{Transplantation procedure}

The transplantation procedure was successful and was completed seven times. The patient received $1.5 \mathrm{mLs}$ volume of PRP containing approximately 30-60 million cells in each gland followed by six repeat injections of pure ADSCs (approximately 2.5 million cells in each) in $1.5 \mathrm{mLs}$ of PRP. A volume of approximately $1.5 \mathrm{mLs}$ of cells in PRP was placed directly into the salivary glands as determined by ultrasound. The glands were visible on the ultrasound monitor, and needle placement was confirmed in the center of the gland. Table 1 presents a summary of injections completed with the corresponding dates and time line.

\section{Efficacy outcomes}

The patient reported an increase in saliva production over the 31-month follow-up period. In addition, the glands increased in size from baseline to 31 months as shown in Table 2. 
Table I Summary of treatment dates

\begin{tabular}{lll}
\hline Treatment & Date & Timeline \\
\hline Pre-SVF & 23-Apr-14 & Baseline \\
Ist MSC & 20-Sep-14 & 5 months \\
2nd MSC & 9-Dec-14 & 8 months \\
3rd MSC & 12-Aug-15 & 16 months \\
4th MSC & 7-Oct-15 & 18 months \\
5th MSC & 9-Mar-16 & 23 months \\
6th MSC & 24-Aug-16 & 28 months \\
7th MSC & 30-Nov-16 & 31 months \\
\hline
\end{tabular}

Abbreviations: SVF, stromal vascular fraction; MSC, mesenchymal stem cell.

The glands increased approximately $2-4 \mathrm{~mm}$ in size from baseline. The patient also reported overall improvements in quality of life.

\section{Safety analysis}

No severe adverse events were reported throughout the monitoring. The patient did not report any other events.

\section{Discussion}

Xerostomia postradiation includes severe dry mouth, and current clinical options are limited. Promising preclinical results using cellular medicine have been reported in the literature. SVF followed by repeat dosing with cultureexpanded ADSCs may be a feasible therapy for this debilitating condition. Utilizing an ultrasound-guided technique and local anesthesia, the cells can be easily placed directly into the glands. The volume of PRP that can be added to the glands is limited to about 1-2 mLs due to structural size. Additional studies with larger sample sizes could determine appropriate ADSC dosing (i.e., number of cells) and timing.

The use of stem cells to repair damaged tissue is a novel approach, and the true mechanisms of action are not fully understood at this point. It is unclear if the injected stem cells engraft and contribute to the formation of tissue or if benefits are created by a paracrine/immunomodulatory effect. The clinical efficacy is most likely due to a cascade of events stimulated by the injected growth factors associated with both the PRP and the stem cells. The complex interaction of the growth factors may lead to reduced inflammation and stimulate new tissue formation.

This first-in-man case demonstrated the safety and feasibility of direct injection of SVF and ADSCs in PRP in a severe xerostomia patient. The procedure was well tolerated, and no major safety events were reported. In addition, the patient demonstrated an increase in gland size as calculated by ultrasound with corresponding clinical response of increased saliva production. Because this case study suggested that SVF and serial ADSC injections were safe and feasible, future studies are warranted to determine the efficacy. Large clinical studies could establish the expected outcomes and efficacy of the therapy. Larger double-blind studies could address theoretical safety concerns such as teratoma formation or interference with the immune system (i.e., immunosuppression).

\section{Abbreviations}

ADSC, adipose-derived stem cell; MSC, mesenchymal stem cell; PRF, platelet-rich fibrin; PRP, platelet-rich plasma; SVF, stromal vascular fraction.

\section{Acknowledgments}

This study was partially funded by South African Stem Cell Institute and US Stem Cell, Inc.

\section{Author contributions}

$\mathrm{KC}$ and $\mathrm{WB}$ designed the protocol. WB was responsible for clinical procedures and follow-up of patients. $\mathrm{KC}$ analyzed the data and wrote the manuscript. Both the authors read and approved the final manuscript. All authors contributed toward data analysis, drafting and revising the paper and agree to be accountable for all aspects of the work.

\section{Disclosure}

$\mathrm{KC}$ is an officer of US Stem Cell, Inc. US Stem Cell is a publicly traded company providing physician-based stem cell

Table 2 Summary of gland size as measured by ultrasound

\begin{tabular}{|c|c|c|c|c|c|}
\hline \multirow[b]{2}{*}{ Treatment } & \multirow[b]{2}{*}{ Date } & \multicolumn{4}{|c|}{ Ultrasound measurements } \\
\hline & & $\begin{array}{l}\text { Right submandibular } \\
\text { gland }(\mathrm{mm})\end{array}$ & $\begin{array}{l}\text { Left submandibular } \\
\text { gland }(\mathrm{mm})\end{array}$ & $\begin{array}{l}\text { Right parotid } \\
\text { gland }(\mathrm{mm})\end{array}$ & $\begin{array}{l}\text { Left parotid } \\
\text { gland }(\mathrm{mm})\end{array}$ \\
\hline Pre-SVF & 23-Apr-14 & $31.5 \times 7.6$ & $30 \times 8.7$ & - & - \\
\hline 3rd MSC & 12-Aug-I5 & $32.4 \times 8.2$ & $29.8 \times 8.5$ & $32.9 \times 10.5$ & $33.2 \times 10.3$ \\
\hline 4th MSC & 7-Oct-I5 & $33.9 \times 12.7$ & $32.9 \times 8.8$ & $32.3 \times 15.7$ & $33 \times 15$ \\
\hline 5th MSC & $9-M a r-16$ & $34.4 \times 12.8$ & $31.3 \times 9.1$ & $35.5 \times 17.2$ & $32.9 \times 16.2$ \\
\hline 6th MSC & 24-Aug- 16 & $36.1 \times 13.3$ & $32.7 \times 8.8$ & $38.5 \times 17.3$ & $32.4 \times 16.9$ \\
\hline 7th MSC & $30-N o v-16$ & $34.1 \times 8.5$ & $31.0 \times 8.7$ & $36.4 \times 13.3$ & $36.8 \times 13.0$ \\
\hline
\end{tabular}

Abbreviations: SVF, stromal vascular fraction; MSC, mesenchymal stem cell. 
therapies to human and animal patients as well as a developer of autologous cell therapies. WB reports no conflict of interest in this work.

\section{References}

1. Acauan MD, Figueiredo MA, Cherubini K, Gomes AP, Salum FG. Radiotherapy-induced salivary dysfunction: structural changes, pathogenetic mechanisms and therapies. Arch Oral Biol. 2015;60(12):1802-1810.

2. Yoo C, Vines JB, Alexander G, Murdock K, Hwang P, Jun HW. Adult stem cells and tissue engineering strategies for salivary gland regeneration: a review. Biomater Res. 2014;18(1):9.

3. Ogawa M, Tsuji T. Functional salivary gland regeneration as the next generation of organ replacement regenerative therapy. Odontology. 2015;103(3):248-257.

4. Patel VN, Hoffman MP. Salivary gland development: a template for regeneration. Semin Cell Dev Biol. 2014;25-26:52-60.

5. Jensen DH, Oliveri RS, Trojahn Kølle SF, et al. Mesenchymal stem cell therapy for salivary gland dysfunction and xerostomia: a systematic review of preclinical studies. Oral Surg Oral Med Oral Pathol Oral Radiol. 2014;117(3):335-342.e1.

6. Hematti P, Keating A. Mesenchymal stromal cells in regenerative medicine: a perspective. Mesenchymal Stromal Cells. Springer; New York. 2012:3-16.

7. Przybyt E, Harmsen MC. Mesenchymal stem cells: promising for myocardial regeneration? Curr Stem Cell Res Ther. 2013;8(4):270-277.

8. Nicolay NH, Lopez Perez R, Debus J, Huber PE. Mesenchymal stem cells: a new hope for radiotherapy-induced tissue damage? Cancer Lett. 2015;366(2):133-140.

9. Caplan AI, Correa D. The MSC: an injury drugstore. Cell Stem Cell. 2011;9(1):11-15.

10. Minteer D, Marra KG, Rubin JP. Adipose-derived mesenchymal stem cells: biology and potential applications. Adv Biochem Eng Biotechnol. 2013;129:59-71.

11. Gimble JM, Katz AJ, Bunnell BA. Adipose-derived stem cells for regenerative medicine. Circ Res. 2007;100(9):1249-1260.

12. Rehman J, Traktuev D, Li J. Secretion of angiogenic and antiapoptotic factors by human adipose stromal cells. Circulation. 2004;109(10):1292-1298.

13. Traktuev DO, Merfeld-Clauss S, Li J, et al. A population of multipotent CD34-positive adipose stromal cells share pericyte and mesenchymal surface markers, reside in a periendothelial location, and stabilize endothelial networks. Circ Res. 2008;102(1):77-85.

14. Comella K, Silbert R, Parlo M. Effects of the intradiscal implantation of stromal vascular fraction plus platelet rich plasma in patients with degenerative disc disease. J Transl Med. 2017;15(1):12.

15. Comella K, Parcero J, Bansal H, et al. Effects of the intramyocardial implantation of stromal vascular fraction in patients with chronic ischemic cardiomyopathy. J Transl Med. 2016;14(1):158.
16. Michalek J, Moster R, Lukac L, et al. Autologous adipose tissue-derived stromal vascular fraction cells application in patients with osteoarthritis. Cell Transplant. Epub 2015 Jan 20. doi: 10.3727/096368915X686760.

17. Panfilov IA, de Jong R, Takashima S, Duckers HJ. Clinical study using adipose-derived mesenchymal-like stem cells in acute myocardial infarction and heart failure. Methods Mol Biol. 2013;1036:207-212.

18. Jang Y, Koh YG, Choi YJ, et al. Characterization of adipose tissuederived stromal vascular fraction for clinical application to cartilage regeneration. In Vitro Cell Dev Biol Anim. 2015;51(2):142-150.

19. Aust L, Devlin B, Foster SJ, et al. Yield of human adipose-derived adult stem cells from liposuction aspirates. Cytotherapy. 2004;6(1):7-14.

20. Lombaert I, Movahednia MM, Adine C, Ferreira JN. Concise review: salivary gland regeneration: therapeutic approaches from stem cells to tissue organoids. Stem Cells. 2016;35(1):97-105.

21. Nevens D, Nuyts S. The role of stem cells in the prevention and treatment of radiation-induced xerostomia in patients with head and neck cancer. Cancer Med. 2016;5(6):1147-1153.

22. Wang Z, Ju Z, He L, Li Z, Liu Y, Liu B. Intraglandular transplantation of adipose-derived stem cells for the alleviation of irradiation-induced parotid gland damage in miniature pigs. J Oral Maxillofac Surg. Epub 2016 Aug 16. doi: 10.1016/j.joms.2016.08.001.

23. Kagami $H$. The potential use of cell-based therapies in the treatment of oral diseases. Oral Dis. 2015;21(5):545-549.

24. An HY, Shin HS, Choi JS, Kim HJ, Lim JY, Kim YM. Adipose mesenchymal stem cell secretome modulated in hypoxia for remodeling of radiation-induced salivary gland damage. PLoS One. 2015;10(11):e0141862.

25. Kawakami M, Ishikawa H, Tanaka A, Mataga I. Induction and differentiation of adipose-derived stem cells from human buccal fat pads into salivary gland cells. Hum Cell. 2016;29(3):101-110.

26. Lee J, Park S, Roh S. Transdifferentiation of mouse adipose-derived stromal cells into acinar cells of the submandibular gland using a coculture system. Exp Cell Res. 2015;334(1):160-172.

27. Liang L, Wang J, Zhang Y, et al. Transdifferentiation of bone marrowderived mesenchymal stem cells into salivary gland-like cells using a novel culture method. Biotechnol Lett. 2015;37(7):1505-1513.

28. Fang D, Hu S, Liu Y, Quan V-H, Seuntjens J, Tran SD. Identification of the active components in Bone Marrow Soup: a mitigator against irradiation-injury to salivary glands. Sci Rep. 2015;5(1):16017.

29. Schwarz S, Huss R, Schulz-Siegmund M, et al. Bone marrow-derived mesenchymal stem cells migrate to healthy and damaged salivary glands following stem cell infusion. Int J Oral Sci. 2014;6(3):154-161.

30. Xiong X, Shi X, Chen F. Human adipose tissue-derived stem cells alleviate radiation-induced xerostomia. Int J Mol Med. 2014;34(3):749-755.

31. Chen Y, Niu Z, Xue Y, Yuan F, FuY, Bai N. Improvement in the repair of defects in maxillofacial soft tissue in irradiated minipigs by a mixture of adipose-derived stem cells and platelet-rich fibrin. Br J Oral Maxillofac Surg. 2014;52(8):740-745.
International Medical Case Reports Journal

\section{Publish your work in this journal}

The International Medical Case Reports Journal is an international, peer-reviewed open-access journal publishing original case reports from all medical specialties. Previously unpublished medical posters are also accepted relating to any area of clinical or preclinical science. Submissions should not normally exceed 2,000 words or

\section{Dovepress}

4 published pages including figures, diagrams and references. The manuscript management system is completely online and includes a very quick and fair peer-review system, which is all easy to use. Visit $\mathrm{http}: / /$ www.dovepress.com/testimonials.php to read real quotes from published authors. 